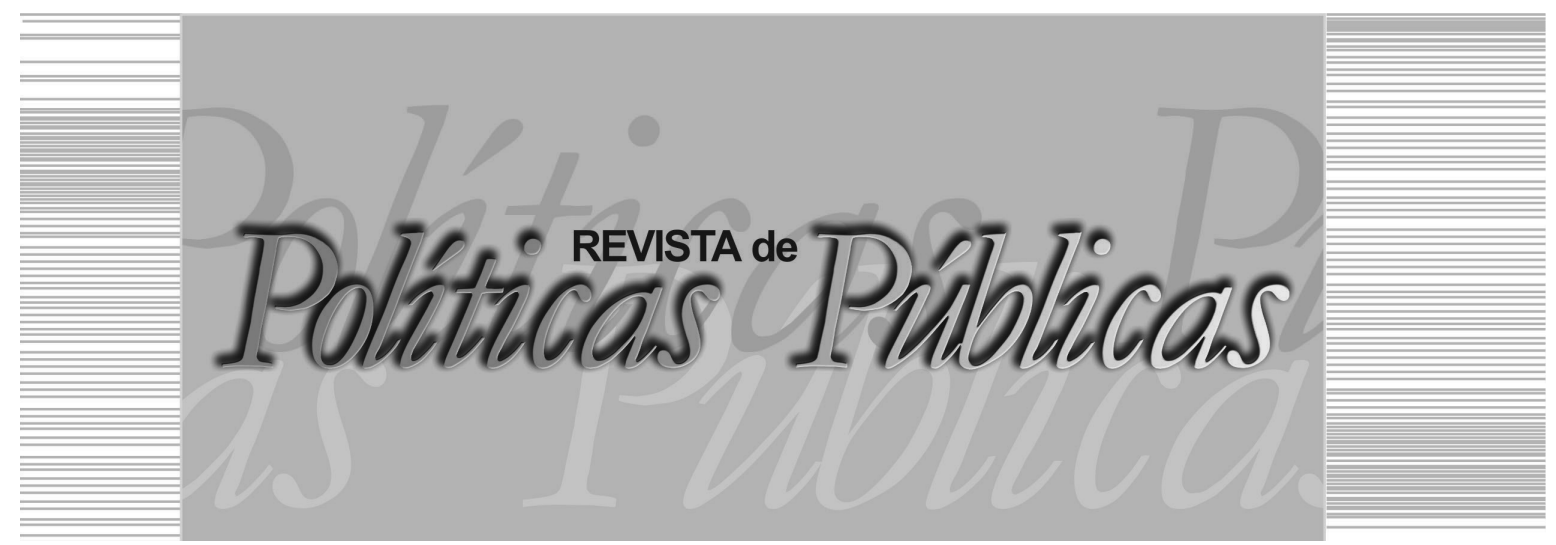

\title{
ANÁLISE DA EVOLUÇÃO DO IMPOSTO SOBRE SERVIÇOS NA ARRECADAÇÃO TRIBUTÁRIA NO MUNICÍPIO DE CAMPINAS-SPI
}

\author{
Josmar Cappa \\ Pontifícia Universidade Católica de Campinas (PUC-Campinas) \\ José Vicente de Souza Filho ${ }^{2}$ \\ Pontifícia Universidade Católica de Campinas (PUC-Campinas)
}

\section{Resumo}

O artigo analisa a importância do Aeroporto Internacional de Viracopos para a arrecadação tributária do município de Campinas-SP. Para isso, foi feita discussão teórica sobre o papel estratégico de grandes aeroportos na dinâmica da economia contemporânea e reconstituído o debate sobre a estrutura tributária brasileira para destacar, a partir da Constituição Federal de 1988, a descentralização tributária para estados e municípios e a elaboração dos orçamentos públicos no país. A análise constata que a evolução da arrecadação tributária em Campinas foi recuperada entre 1995 e 2013 a partir de informações primárias da Secretaria Municipal de Finanças. Concluiu-se que Viracopos foi importante no desempenho do ISS, apesar de não ser exclusivo, e que estamos diante de nova tendência na arrecadação tributária, tornando-se necessária a instituição de políticas públicas de gestão aeroportuária.

Palavras-chave: Políticas Públicas, desenvolvimento local, transporte aéreo, aeroporto.

\footnotetext{
1 Economista, Doutor em Economia pela Universidade Estadual de Campinas (UNICAMP), Professor e Pesquisador no Centro de Economia e Administração (CEA) da Pontifícia Universidade Católica de Campinas (PUC-Campinas). Email: josmar.cappa@puccampinas.edu.br/josmarcappa@gmail.com

2 Contador, Mestre em Ciências Contábeis e Atuariais pela PUC-SP, Professor e Diretor da Faculdade Ciências Contábeis do Centro de Economia e Administração (CEA) da PUC-Campinas. Email: josé.vicente@puc-campinas.edu.br / Pontifícia Universidade Católica de Campinas - PUC-Campinas: Campus I - Prédio da Reitoria Rod. D. Pedro I, km 136, Pq. das Universidades Campinas - SP. CEP: 13086-900
} 


\title{
ANALYSIS OF THE EVOLUTION OF TAX ON SERVICES IN TAX COLLECTION IN CAMPINAS-SP MUNICIPALITY
}

\begin{abstract}
The objective of this paper was to analyze the importance of Viracopos International Airport to the tax collection in the city of Campinas-SP. For this, it was made a theoretical discussion on the strategic role of airports in the dynamics of the contemporary economy, and recovered the debate on the Brazilian tax structure to highlight, from the 1988 Federal Constitution, the tax decentralization to states and municipalities and the elaboration of public budgets in the country. The historical evolution of tax revenue in Campinas was recovered between 1995 and 2013 from primary information from the Municipal Finance. It was concluded that Viracopos was important in the performance of the Tax on Services, although not exclusive, and that we are facing new trend in tax revenues, making necessary the establishment of public policies for airport management.
\end{abstract}

Key words: Public Policies, local development, air transport, airports.

\section{INTRODUÇÃO}

Neste estudo pretendeu-se analisar a importância do Aeroporto Internacional de Viracopos para a arrecadação tributária do município de Campinas-SP, onde esse aeroporto está localizado, devido à concessão da administração de Viracopos, desde 2012, para empresa privada Aeroportos Brasil Viracopos S/A.

Com essa concessão, a empresa Aeroportos Brasil Viracopos S/A, que presta serviços públicos de transporte de mercadorias e de passageiros, passou obrigatoriamente a pagar impostos como, por exemplo, o Imposto sobre Serviços de Qualquer Natureza (ISSQN) para o município de Campinas-SP. Até então, gestora de Viracopos, a Empresa Brasileira de Infraestrutura Aeroportuária (Infraero), por definição legal, não era obrigada a pagar impostos.

Este estudo está dividido em três partes. A primeira refere-se ao marco teórico sobre a estrutura tributária no Brasil e a importância da descentralização dos tributos para estados e municípios, possibilitando-lhes maior autonomia na arrecadação e na prestação de serviços públicos como saúde e educação. Por isso, destacou-se também a importância da elaboração e da execução do orçamento público no planejamento das ações por meio do Plano Plurianual (PPA), da Lei de Diretrizes Orçamentárias (LDO) e das Leis Orçamentárias Anuais (LOAS). 


\section{ANÁLISE DA EVOLUÇÃO DO IMPOSTO SOBRE SERVIÇOS NA ARRECADAÇÃO TRIBUTARIA NO MUNICÍPIO DE CAMPINAS-SP}

A segunda parte refere-se à apresentação da metodologia de estudo utilizada para fundamentar a análise de dados empíricos, tendo presente a recuperação do supracitado debate teórico.

A terceira parte analisa as relações econômicas entre Campinas e o Aeroporto de Viracopos, devido à sua participação expressiva na incidência do ISSQN para o município. Nessa parte, contou-se com informações empíricas sobre o fluxo de passageiros e de mercadorias exportadas e importadas por Viracopos, comparando-o aos principais aeroportos paulistas (Guarulhos e Congonhas).

Essa parte foi finalizada por meio de análise sobre a evolução do ISSQN na estrutura tributária de Campinas entre 1995 e 2013. O intuito foi de compreender a participação de Viracopos no desempenho do ISSQN, comparando esse tributo com os demais tributos municipais como, por exemplo, o Imposto sobre Propriedade Predial e Territorial (IPTU), Imposto sobre a Propriedade de Veículos Automotores (IPVA) e o Imposto sobre Circulação de Mercadorias e Prestação de Serviços (ICMS).

\section{FUNDAMENTAÇÃO TEÓRICA}

\subsection{A estrutura tributária brasileira}

A estrutura tributária brasileira está determinada pela Constituição Federal (CF) de 1988, que dispõe sobre os princípios gerais, as limitações do poder de tributar, as competências e a repartição das receitas tributárias. Depois da centralização tributária, instituída pelo governo federal por meio da Reforma Tributária de 1966, o país adotou o princípio de autonomia político-administrativa, ao conceder a cada esfera de governo a possibilidade de instituir impostos e taxas (em razão do poder de polícia ou pela utilização de serviços públicos) e contribuições para melhorias (decorrentes de obras públicas). As contribuições sociais, no entanto, em sua maioria, somente podem ser instituídas pelo Governo Federal. (TRISTÃO, 2003).

A CF de 1988, em vigor, marcou, portanto, a descentralização tributária para estados e municípios, com intuito de atender ao anseio nacional de possibilitar condições reais para o resgate da dívida social, marcada, especialmente, por demandas populares por saúde, educação, habitação e transporte. $\mathrm{O}$ intuito maior foi de criar um sistema de transferências intergovernamentais que, por um lado, 
possibilitasse melhores condições de arrecadação tributária entre estados e municípios, e, por outro, ajudasse a resolver problemas sociais existentes entre estados e municípios no Brasil. (COSTA; CASTELAR, 2015).

Motivo pelo qual, estados e municípios passaram a ter autonomia administrativa e financeira, na medida em que, do ponto de vista jurídico-institucional, tornaram-se entes federativos. Em contrapartida, pela Constituição de 1988, tornaram-se obrigados a responder, efetivamente, por vários serviços públicos como, por exemplo, saúde, educação e segurança.

A descentralização tributária no Brasil em relação aos estados e municípios é defendida considerando-se a premissa da melhoria do gerenciamento do setor público, pois é no nível local que se teria maior capacidade de alocar eficazmente os recursos públicos, produzindo melhores benefícios espacialmente localizados. (CÓSSIO; CARVALHO, 2001).

Apesar dos avanços instituídos pela CF de 1988, com relação à descentralização tributária, estados e munícipios enfrentam dificuldades financeiras e não cumprem satisfatoriamente o papel que se esperava quanto ao resgate da mencionada dívida social, resultando em tensões entre os entes federativos quanto à repartição da arrecadação tributária no país. (SERRA; AFONSO, 1999). Não obstante, parcela crescente da população, especialmente a de baixa renda, passou a depender, cada vez mais, da capacidade financeira dos municípios e dos repasses da União e dos Estados para terem suas demandas sociais locais atendidas. Porém, no caso da saúde, por exemplo, o que se percebe é a precariedade no atendimento ao cidadão, combinada com a falta de medicamentos, dos básicos aos complexos.

Em razão dessas mudanças, o município teve seu papel alterado, assumindo novas responsabilidades e experimentando novas potencialidades, sendo obrigado a enfrentar, praticamente de forma independente, novos desafios impostos pela necessidade de desenvolvimentos político, econômico e social.

Tal complexidade revela-se maior entre as capitais e cidades importantes em regiões metropolitanas, onde se encontram contingentes populacionais expressivos e parcelas substanciais de baixa renda. Destaque-se que, com a Lei de Responsabilidade Fiscal 


\section{ANÁLISE DA EVOLUÇÃO DO IMPOSTO SOBRE SERVIÇOS NA ARRECADAÇÃO TRIBUTÁRIA NO MUNICÍPIO DE CAMPINAS-SP}

(LRF), este cenário tende ao agravamento, devido, em especial, ao endividamento dos municípios e às suas dificuldades para elevar a capacidade arrecadatória própria. (PEREIRA, 1999).

Certamente, entre a década de 1990 e os anos 2000, as dificuldades do país em manter crescimento sustentável serviram de obstáculos para o crescimento da receita fiscal própria e dos recursos oriundos das transferências constitucionais. Foram importantes também as oscilações da taxa de juros em níveis altos, que elevaram o serviço da dívida e contribuíram para as dificuldades financeiras de vários municípios, principalmente as capitais e cidades importantes em regiões metropolitanas, que tiveram maior acesso a operações de crédito. (FUNDAÇ̃̃O SISTEMA ESTADUAL DE ANÁLISE DE DADOS, 1993).

Essas questões são importantes diante do processo intenso de urbanização no país, sobretudo porque resulta, por um lado, em aumento crescente da necessidade de ofertar serviços públicos para atender, especialmente, demandas sociais geradas pela população de baixa renda. Resulta, por outro lado, no fenômeno da metropolização

[...] e tem levado a que municípios menores [inseridos em regiões metropolitanas], muitas vezes com condições financeiras satisfatórias, acabem delegando a responsabilidade por ofertar serviços sociais como saúde e educação, aos municípios que compõem o núcleo central da região metropolitana, com implicações sobre a qualidade dos serviços, dado que municípios com dificuldades financeiras são forçados a ofertar um volume de serviços maior do que o número de seus habitantes. (LOPREATO; PAIVA, 2001, p. 5).

Esse é o caso de Campinas, por exemplo, que oferece aos municípios localizados em seu entorno, os mencionados serviços de amplitude nacional e internacional (item 4.1)

\subsection{A importância do orçamento público no Brasil}

Em decorrência da descentralização tributária no país, instituída pela CF de 1988, os processos de elaboração e execução do orçamento público passaram a ter lugar de destaque na União, Estados e municípios. A mencionada constituição determina em seu artigo $165^{\circ}$ que todos os entes federativos devem elaborar seus orçamentos públicos amparados: i) pelo inciso $1^{\circ}$ que trata do Plano Plurianual (PPA), que apresenta diretrizes gerais, objetivos e metas 
para um período de três anos de governo e o primeiro do governo subsequente, fixando despesas de capital, outras delas decorrentes e para as relativas aos programas continuados; ii) pelo inciso $2^{\circ}$ sobre a LDO, que estabelece as metas e as prioridades da administração pública, inclusive despesa de capital, e serve como subsídio para a elaboração da LOA para garantir o cumprimento do PPA; e iii) a LOA apresenta o conjunto das receitas e despesas municipais anuais que correspondem à execução do PPA.

Para Sola e Bonacima (2015, p. 33) “"...] o orçamento público tem como um de seus objetivos a tentativa de coordenar e balancear as preferências políticas e os bens públicos contra a limitada disponibilidade de recursos.", justificando sua importância dentro do PPA.

Quanto às receitas municipais, o art. $156^{\circ} \mathrm{da} C \mathrm{CF}$ de $1988 \mathrm{de}-$ termina aos municípios competência para instituir o IPTU, o Imposto sobre Transmissão de Bens e Imóveis (ITBI), o ISSQN, popularmente conhecido por ISS. Os municípios contam também com o Imposto de Renda que fica para o município em função de atividades realizadas no próprio município que geram incidência de retenção na fonte (art. $158^{\circ}$ da mencionada Constituição). Contam ainda com receitas oriundas da taxa de lixo e das transferências constitucionais que são expressivas para os municípios como o IPVA e o ICMS, pelo governo estadual, e os repasses do Sistema Único de Saúde (SUS) e do Fundo para o Desenvolvimento do Ensino Fundamental (FUNDEF) pelo Governo Federal.

A base de arrecadação do IPTU está no cadastro de imóveis mantido pela prefeitura, que gera uma base de valores por zoneamento territorial onde ocorre a incidência do imposto. Existem, entre os municípios brasileiros, dificuldades para manter tal cadastro atualizado. Em Campinas, o IPTU passou de R $\$ 57$ milhões, em 1995, para R \$ 384 milhões em 2013, mas também perde em importância para as transferências constitucionais como o ICMS, por exemplo, que em 1995 representou uma arrecadação de R \$ 156 milhões, passando, em 2013, para R 659 milhões.

O ITBI é um imposto que depende do dinamismo da cidade em termos de compra e venda de imóveis para moradia e para atividades econômicas. Em Campinas não representa um imposto importante em termos de arrecadação. Passou, em 1995, de R \$ 6 milhões para R \$ 89 milhões em 2013, inclusive porque é um imposto 
recolhido em cartórios, mas, normalmente, pelos valores venais dos imóveis e não pelos valores reais negociados entre as partes.

O ISSQN é gerado a partir de atividades econômicas relacionadas à prestação de serviços diversos no município. Em Campinas, esse tributo passou por mudanças importantes no processo de gerenciamento organizado pela prefeitura, e, por ser o objeto de análise deste estudo, será detalhado no item 4 .

\section{METODOLOGIA DO ESTUDO}

$\mathrm{Na}$ literatura especializada sobre técnicas de pesquisa encontram-se diversos autores que defendem como regra a não utilização de um único método de análise. (MAX, 1975; MUNHOZ, 1989; ECO, 1993). Como justificativa, Munhoz $(1989$, p. 89) sugere que "[...] no decorrer do trabalho pode tornar-se necessário, por exemplo, introduzir-se métodos históricos de investigação em relação a determinados pontos, com caráter complementar, sem prejuízo, portanto, de que um outro método tenha sido usado como principal."

Max (1975, p. 47) defende o argumento de que

[...] o método científico não é um só; há diferentes maneiras de proceder para obter resultados científicos. [...] Também há métodos que, por corresponder a princípios básicos de nossa maneira de pensar e investigar, são comuns a todas as ciências, e que, sem variar sua natureza, são aplicáveis às mais diversas matérias.

Nesse estudo foram adotados os métodos objetivo e o método dialético. O primeiro serviu para fundamentar análises, apoiadas em perspectiva teórica, sobre a realidade do fenômeno pesquisado a partir de indícios sinalizados por informações empíricas primárias e/ ou secundárias. (FACHIN, 1993). Serviu, portanto, para organizar e sistematizar as informações empíricas sobre fluxo de passageiros e de mercadorias exportadas e importadas, em Viracopos, bem como a evolução do ISSQN em Campinas, tendo presente a descentralização tributária para estados e municípios, promovida pela CF de 1988.

Tal método foi complementado pelo método dialético, que serviu para analisar os dados empíricos. Assim, foi possível incluir a dimensão do tempo futuro (o devir do objeto), para detalhar como se configura o objeto em seus detalhes (do geral para o particular), compreendendo-o nas relações e condicionantes em que está inseri- 
do (circunstâncias históricas). Trata-se, por um lado, de apreender o objeto de pesquisa na sua própria história ou diacronia, por meio de delimitações temporais (recortes históricos ou horizontais). Por outro, com base na análise sincrônica (recorte vertical), busca-se compreender a dinâmica de reprodução do objeto de pesquisa, por meio de sua identidade e principais variáveis de reprodução. (SELLTIZ et al., 1974).

\section{RESULTADOS E DISCUSSÃO}

\subsection{Relações entre Campinas e o Aeroporto Internacional de Viracopos}

A importância do município de Campinas para o Aeroporto Internacional de Viracopos pode ser analisada pela sua dinâmica econômica, que sempre esteve relacionada à sua localização geográfica estratégica, e pela influência que exerce na própria Região Metropolitana de Campinas (RMC), enquanto sede e principal cidade de uma metrópole classificada, pelo Instituto Brasileiro de Geografia e Estatística (IBGE, 2007), como nacional, devido aos serviços que oferece à população.

Campinas concentra indústrias de alta tecnologia (informática, telecomunicações, química fina e biologia molecular) e centros de ensino e pesquisa como: Universidade Estadual de Campinas (Unicamp); Pontifícia Universidade Católica de Campinas (PUC-Campinas); Centro de Pesquisa de Desenvolvimento em Telecomunicações (CPqD); Companhia de Desenvolvimento Tecnológico (Codetec); Instituto Agronômico de Campinas (IAC); Instituto Tecnológico para Alimentos (ITAL); Coordenadoria de Assistência Técnica Integrada (CATI); Instituto de Zootecnia (IZ); Instituto Biológico (IB); Empresa Brasileira de Pesquisa Agropecuária (Embrapa); Centro Tecnológico de Informática Renato Archer (CTI); Laboratório Nacional de Luz Síncroton (LNLS); Observatório Capricórnio e a Fundação Tropical de Pesquisa e Tecnologia André Tosllo.

Campinas conta ainda com uma estrutura econômica integrada e diversificada, composta pelos setores agrícola, agroindustrial e industrial, com uma infraestrutura complexa (rodovias, ferrovias, os aeroportos de Viracopos e dos Amarais, saneamento ambiental, energia elétrica, gás natural, fibras ópticas) e a mencionada rede de comércio e de serviços diversificados. (CANO; BRANDÃO, 2002). 


\section{ANÁLISE DA EVOLUÇÃO DO IMPOSTO SOBRE SERVIÇOS NA ARRECADAÇÃO TRIBUTÁRIA NO MUNICÍPIO DE CAMPINAS-SP}

O dinamismo atual de Campinas fica evidenciado pela sua capacidade de atrair investimentos produtivos diversificados, especialmente os de maior complexidade tecnológica como telecomunicações, equipamentos médicos, automobilística e petroquímica. Entre as razões manifestadas pelas empresas que se instalam em Campinas estão a existência de infraestrutura integrada, sistema multimodal de transporte, com destaque para o Aeroporto Internacional de Viracopos e proximidade geográfica com o Porto de Santos, além de instituições de ciência e tecnologia e mão de obra qualificada disponível.

A RMC é composta por 20 municípios (Lei n ${ }^{\circ} 870$, de 19 de junho de 2000), que constituem uma estrutura econômica e social importante no país, na medida em que compõem um território de aproximadamente $3.673 \mathrm{~km}^{2}$, onde vivem cerca de 2,8 milhões de habitantes (1,46\% do Brasil ou 6,8\% do Estado de São Paulo). Constituiu um Produto Interno Bruto (PIB) estimado em US\$ 49 bilhões em 2009, o que representa 7,9\% do PIB do Estado de São Paulo e $2,7 \%$ do PIB nacional.

A maior parte da população da RMC $(38,6 \%)$ encontra-se em Campinas, que possui pouco mais de um milhão de habitantes, além de um PIB de US\$ 18,1 bilhões em 2009. Predomina, portanto, a existência de municípios de tamanho médio, entre 100 mil e 250 mil habitantes, com destaque para Sumaré, Americana, Indaiatuba, Hortolândia, Santa Barbara D'Oeste, Valinhos e Itatiba. Entre as cidades com 50 e 500 mil habitantes encontram-se onze municípios, que apresentam uma taxa de urbanização acima de $95 \%$, próxima à de Campinas, que é de $98 \%$. Apenas os municípios de Engenheiro Coelho e Holambra possuem menos de 20 mil habitantes.

O município de Campinas tornou-se sede e o principal da RMC porque apresenta características econômicas de estado e em algumas atividades oferece serviços de amplitude internacional e nacional como a presença do Aeroporto de Viracopos, dos hospitais da Unicamp e da PUC-Campinas, da rede de comércio e serviços instalada no entorno da Rodovia D. Pedro I com grandes shoppings centers (Galeria, Iguatemi, D. Pedro), hipermercados, escritórios de comércio exterior, empresas de transporte e logística e centros de inovação tecnológica. Essa rede de comércio e de serviços fornece apoio às atividades produtivas como armazenamento, transportes, comercialização, exportação, importação, finanças, comunicações, propaganda, publicidade e consultorias diversas, que atrai signifi- 
cativo fluxo de pessoas, mercadorias e movimentação financeira. (CAPPA, 2008).

Nos próximos trinta anos, desde junho de 2012, a administração de Viracopos está sob a responsabilidade da Aeroportos Brasil S/A. O cumprimento do contrato de concessão implica investimentos de R \$ 8,4 bilhões, de acordo com a evolução da demanda por passageiros, podendo ter capacidade para transportar 80 milhões de passageiros e pouco mais de 1 milhão de toneladas em 2038.

O potencial de demanda reprimida por transporte de passageiros em Viracopos foi evidenciado pelo spill de tráfego em direção a este aeroporto oriundo do Aeroporto de Congonhas desde 2007, devido às suas restrições operacionais com o acidente da empresa TAM. Foi importante também a redução da oferta de slots (espaços para aeronaves) nos principais aeroportos brasileiros. Foi decisivo, contudo, a empresa Azul Linhas Aéreas que escolheu Viracopos como centro de suas operações desde o final de 2008.

Em 2003, a demanda por passageiros em Viracopos era de 655 mil. Com as operações da Azul, essa demanda chegou a 9.846.853 em 2014. Congonhas manteve-se próximo de sua capacidade operacional máxima ao passar de 12.069.575, em 2003, para 18.146. 405 em 2014, depois de uma redução para cerca de 13,6 milhões devido à restrição dos slots, como mencionado. Entre 2003 e 2014, o Aeroporto de Guarulhos passou de 11.581 .034 para 39.538 .000 passageiros, mantendo-se em primeiro lugar no país, especialmente porque é o que mais oferece rotas aéreas internacionais regulares (Tabela 1).

Tabela 1 - Passageiros nos aeroportos de Guarulhos, Congonhas e Viracopos - 2003-2014

\begin{tabular}{c|c|c|c|c|c|c}
\hline Aeroporto & 2003 & 2004 & 2005 & 2006 & 2007 & 2008 \\
\hline Guarulhos & 11.581 .034 & 12.940 .193 & 15.834 .797 & 15.759 .181 & 18.795 .596 & 20.400 .304 \\
\hline Congonhas & 12.069 .575 & 13.611 .227 & 17.147 .628 & 18.459 .191 & 15.265 .433 & 13.672 .301 \\
\hline Viracopos & 654.768 & 717.362 & 816.599 & 826.246 & 1.006 .059 & 1.083 .878 \\
\hline Aeroporto & 2009 & 2010 & 2011 & 2012 & 2013 & 2014 \\
\hline Guarulhos & 21.727 .649 & 26.849 .185 & 30.003 .428 & 32.777 .330 & 36.055 .063 & 39.538 .000 \\
\hline Congonhas & 13.699 .657 & 15.499 .462 & 16.756 .452 & 16.775 .770 & 17.119 .530 & 18.146 .405 \\
\hline Viracopos & 3.364 .404 & 5.430 .066 & 7.568 .384 & 8.858 .380 & 9.295 .808 & 9.846 .853 \\
\hline
\end{tabular}

Fonte: Elaborada pelos autores, conforme informações de Infraero (2015), Viracopos (2015) e Guarulhos (2015). 


\section{ANÁLISE DA EVOLUÇÃO DO IMPOSTO SOBRE SERVIÇOS NA ARRECADAÇÃO TRIBUTÁRIA NO MUNICÍPIO DE CAMPINAS-SP}

Além de receber parte da movimentação de passageiros no país, Viracopos exerce funções de logística industrial para empresas que atuam em redes no mercado mundial. Assim, agrega valor às mercadorias na medida em que organiza os fluxos do estoque mínimo da grande empresa, ampliando a geração, direta e indireta, de emprego, renda e tributos na RMC. (CAPPA, 2013).

O destaque na movimentação de mercadorias ficou para os aeroportos de Guarulhos e Viracopos, ambos localizados no Estado de São Paulo. O primeiro porque dispõe de maior número de rotas aéreas internacionais, e Viracopos porque se constituiu como centro cargueiro para empresas aéreas internacionais. Porém, entre 1996 e 2014, o desempenho histórico entre esses dois aeroportos aponta para melhor evolução de Viracopos nas importações, enquanto que, em igual período, nas exportações de mercadorias, ambos tiveram perdas relativas devido à crise internacional de 2008, com pequena recuperação para Viracopos.

Considerando-se os valores em Dólares, gerados pela movimentação de mercadorias importadas no país, Viracopos ocupava a sexta posição, em 1996, e estabilizou-se na segunda posição desde 1998, estando atrás somente do Porto de Santos. A participação absoluta de Viracopos quintuplicou ao passar de US\$ 2,6 bilhões (4,9\%), em 1996, para US\$14,5 bilhões em 2012 (6,52\%), mantendo, desde 2007, valores superiores a US\$ 10 bilhões, alcançando, em 2014, a US\$ 17,0 bilhões. Guarulhos oscilou entre a terceira e a quarta posição, com crescimento absoluto de US\$ 4,3 bilhões para US\$ 10,9 bilhões (4,91\%) em 2012, mas passou para a quinta e a sexta posições relativas, respectivamente, entre 2011 e 2012 e entre 2013 e 2014 (Tabela 2). 
Tabela 2 - Comparação entre Viracopos e Guarulhos nas importações - 1996-2014

\begin{tabular}{|c|c|c|c|c|c|c|c|c|}
\hline & 1996 & 1997 & & 1998 & 1999 & 2000 & 2001 & 2002 \\
\hline Total País - USS bi Fob & 53,4 & 59,8 & & 57,8 & 49,3 & 55,9 & 55,7 & 47,3 \\
\hline Aeroportos & US\$ R \% & USS R $\%$ & & $\mathrm{R} \quad \%$ & USS $\mathrm{R} \quad \%$ & US\$ $\mathrm{R} \quad \%$ & US\$ R $\%$ & US\$ R $\%$ \\
\hline Guarulhos Importação & $4,3 \quad 3 \quad 8,0$ & $4,4 \quad 3 \quad 7,3$ & & $\begin{array}{ll}4 & 7,1\end{array}$ & $3,3 \quad 4 \quad 6,7$ & $3,2 \quad 3 \quad 5,7$ & $3,3 \quad 4 \quad 5,8$ & $2,6 \quad 4 \quad 5,5$ \\
\hline Viracopos Importação & $2,6 \quad 6 \quad 4,9$ & $4,4 \quad 4 \quad 7,3$ & 5,5 & $2 \quad 9,7$ & $6,2 \quad 2 \quad 12,5$ & $\begin{array}{lll}7,5 & 2 & 13,4 \\
\end{array}$ & $7,2 \quad 2 \quad 12,9$ & $4,4 \quad 2 \quad 9,3$ \\
\hline & 2003 & 2004 & & 2005 & 2006 & 2007 & 2008 & 2009 \\
\hline Total País - USS bi Fob & 48,4 & 62,9 & & 73,6 & 91,4 & 120,6 & 173,2 & 127,8 \\
\hline Aeroportos & US\$ R \% & US\$ R \% & US\$ & $\mathrm{R} \quad \%$ & USS R $\%$ & US\$ $\mathrm{R} \quad \%$ & US\$ $\mathrm{R} \quad \%$ & US\$ R $\%$ \\
\hline Guarulhos Importação & $2,9 \quad 3 \quad 5,9$ & $\begin{array}{lll}3,7 & 3 & 5,9\end{array}$ & 4,6 & 36,2 & $6,1 \quad 3 \quad 6,7$ & $7,6 \quad 3 \quad 6,3$ & $10,1 \quad 4 \quad 5,6$ & $7,9 \quad 3 \quad 6,21$ \\
\hline Viracopos Importação & $4,3 \quad 2 \quad 8,8$ & $6,3 \quad 2 \quad 9,9$ & 6,9 & 29,4 & $8,2 \quad 2 \quad 9,0$ & $10,1 \quad 2 \quad 8,4$ & $12,8 \quad 2 \quad 7,3$ & $10,7 \quad 28,36$ \\
\hline & 2010 & 2011 & & 2012 & 2013 & 2014 & & \\
\hline Total País - USS bi Fob & \begin{tabular}{|l|}
196 \\
\end{tabular} & \begin{tabular}{|l|}
226,3 \\
\end{tabular} & & 223,2 & \begin{tabular}{|l|}
239,6 \\
\end{tabular} & \begin{tabular}{|l|}
229,1 \\
\end{tabular} & & \\
\hline Aeroportos & US\$ R \% & US\$ R \% & US\$ & $\mathrm{R} \%$ & USS R \% & US\$ R \% & & \\
\hline Guarulhos Importação & $10,0 \quad 4 \quad 5,13$ & $11,5 \quad 5 \quad 5,09$ & 10,9 & 54,91 & $\begin{array}{lll}10,9 & 6 & 4,53\end{array}$ & $10,5 \quad 6 \quad 4,58$ & & \\
\hline Viracopos Importação & $13,5 \quad 2 \quad 6,89$ & $15,0 \quad 2 \quad 6,65$ & 14,5 & 36,52 & $\begin{array}{lll}16 & 2 & 6,69 \\
\end{array}$ & $\begin{array}{llll}17,0 & 2 & 7,44 \\
\text {. }\end{array}$ & & \\
\hline
\end{tabular}

Fonte: Elaborada pelos autores, conforme informações do Ministério de Desenvolvimento, Indústria Comércio Internacional (MDIC, 2015).

Nota: $\mathrm{R}=$ Ranking.

O melhor desempenho de Viracopos, nas importações, está relacionado ao spill de tráfego em direção a esse aeroporto, especialmente de voos cargueiros regulares semanais, porque, para essa demanda, a distância em torno de $100 \mathrm{~km}$ da Capital do Estado de São Paulo, como é o caso de Viracopos, não constitui obstáculo importante.

Ademais, Viracopos recebeu investimentos para ampliar e modernizar seu terminal de exportação (1995-2003) e o de importação (1996-2004), além da instalação do terminal de carga expressa (2003-2004) e do sistema de transelevador (2001-2004) para armazenar mercadorias em 513 posições (verticais e horizontais) por meio de automação e código de barras, garantindo rapidez, segurança e confiabilidade no trâmite de liberação de mercadorias (Visita Técnica ao Aeroporto de Viracopos realizada em 30 de setembro de 2013).

Além de automatizado, o Terminal de Importação tem 40.000 $\mathrm{m}^{2}$ e o de Exportação tem $10.200 \mathrm{~m}^{2}$, possibilitando maior competitividade de Viracopos frente aos demais terminais de cargas no país e aeroportos inseridos em regiões industrializadas como, por exemplo, o de São José dos Campos. Este aeroporto, que está a $120 \mathrm{~km}$ da capital paulista, não consegue expandir suas operações cargueiras, apesar de ter sido classificado como internacional pelo Departamen- 


\section{ANÁLISE DA EVOLUÇÃO DO IMPOSTO SOBRE SERVIÇOS NA ARRECADAÇÃO TRIBUTÁRIA NO MUNICÍPIO DE CAMPINAS-SP}

to de Aviação Civil (DAC), desde 4 de janeiro de 2000, e de servir de apoio às atividades da Empresa Brasileira de Aeronáutica S.A. (Embraer), a $4^{\mathrm{a}}$ na indústria aeronáutica mundial e líder na fabricação de jatos regionais.

Para exportações de mercadorias no Brasil, também avaliadas pela geração de Dólares, Viracopos ocupa a segunda posição entre os aeroportos desde 2003. Perde apenas para Guarulhos que lidera a oferta de voos internacionais para passageiros no país, mas que também são utilizados para transporte de mercadorias de volumes menores. Entre 1996 e 2014 tanto o Aeroporto de Guarulhos, quanto o de Viracopos, praticamente, mantiveram suas posições no ranking nacional sobre movimentação de mercadorias exportadas. Guarulhos, que ocupava a $7^{\mathrm{a}}$ posição (US\$ 2,3 bilhões), em 1996, oscilou entre a $8^{\mathrm{a}}$ e a $10^{\mathrm{a}}$ posição entre 2004 e 2012 , passando em 2013 e 2014 a ocupar a sétima posição no ranking nacional com a geração de US\$ 8 bilhões em mercadorias exportadas.

Entre 1996 e 2014, Viracopos aumentou em seis vezes a geração de valores em Dólares com exportações, ao passar de US\$ 560 milhões ( $15^{\mathrm{a}}$ posição) para cerca de US\$ 3,4 bilhões, mantendo-se entre a $13^{\mathrm{a}}$ e $14^{\mathrm{a}}$ posição, mas, devido à contração de demanda gerada pela crise econômica internacional de 2008 , caiu para $18^{\mathrm{a}} \mathrm{em}$ 2012, para $17^{\mathrm{a}}$ posição relativa em 2013 e para a $16^{\mathrm{a}}$ posição em 2014 (Tabela 3).

Tabela 3- Comparação entre Viracopos e Guarulhos nas exportações - 1996-2014

\begin{tabular}{|c|c|c|c|c|c|c|c|c|c|c|c|c|}
\hline & \multirow{2}{*}{\multicolumn{2}{|c|}{$\begin{array}{c}\mathbf{1 9 9 6} \\
47.8\end{array}$}} & \multicolumn{2}{|r|}{1997} & \multicolumn{2}{|r|}{1998} & \multicolumn{2}{|r|}{1999} & \multirow{2}{*}{\multicolumn{2}{|c|}{2000}} & \multirow{2}{*}{\begin{tabular}{|l|}
2001 \\
523
\end{tabular}} & \multirow{2}{*}{$\frac{\mathbf{2 0 0 2}}{60.5}$} \\
\hline Total País - US\$ bi Fob & & & & 53 & & 51,2 & & 48,1 & & & & \\
\hline Aeroportos & & $\$ R \%$ & & R $\%$ & & $\$ \mathrm{R} \%$ & & $\$ R \quad \%$ & US: & $\$$ R $\%$ & US\$ R $\%$ & US\$ $\mathrm{R} \quad \%$ \\
\hline Guarulhos Exportação & & 74,8 & 2,6 & $\begin{array}{ll}7 & 4,9\end{array}$ & 2,2 & $7 \quad 4,3$ & & 75,2 & 2,9 & $6 \quad 5,3$ & $3,3 \quad 5 \quad 5,7$ & $\begin{array}{lll}3 & 5 & 5\end{array}$ \\
\hline \multirow[t]{2}{*}{ Viracopos Exportação } & & $\begin{array}{ll}15 & 1,1 \\
\end{array}$ & 670 & $15 \quad 1,3$ & & $\begin{array}{ll}15 & 1,4 \\
\end{array}$ & 746 & $13 \quad 1,6$ & 1,9 & $\begin{array}{ll}8 & 3,4 \\
\end{array}$ & $\begin{array}{lll}1,7 & 11 & 2,9 \\
\end{array}$ & $\begin{array}{lll}1 & 14 & 1,7 \\
\end{array}$ \\
\hline & & 2003 & \multicolumn{2}{|r|}{2004} & \multicolumn{2}{|r|}{2005} & \multicolumn{2}{|r|}{2006} & \multicolumn{2}{|r|}{2007} & 2008 & 2009 \\
\hline Total País - US\$ bi Fob & \multicolumn{2}{|r|}{73,2} & \multicolumn{2}{|r|}{96,7} & \multicolumn{2}{|r|}{187,5} & \multicolumn{2}{|r|}{137,8} & \multicolumn{2}{|r|}{160,6} & 197,9 & 152,9 \\
\hline Aeroportos & & $\$ \mathrm{R} \%$ & & $\$ R \quad \%$ & & $\$ R \%$ & & $\$ R \quad \%$ & & $\$$ R $\%$ & US\$ R \% & US\$ R \% \\
\hline Guarulhos Exportação & & 73,8 & & 93,3 & & 93,41 & & 93,3 & 4,9 & 103,0 & $5,7 \quad 102,89$ & $5,2 \quad 8 \quad 3,40$ \\
\hline \multirow[t]{2}{*}{ Viracopos Exportação } & & 131,9 & & 132,05 & & $12 \quad 2,4$ & & $\begin{array}{ll}10 & 2,7 \\
\end{array}$ & 3,8 & $\begin{array}{ll}11 & 2,4 \\
\end{array}$ & $4,0 \quad 13 \quad 2,02$ & $2,8 \quad 15 \quad 1,79$ \\
\hline & & 2010 & & 2011 & & 2012 & & 2013 & & 2014 & & \\
\hline Total País - US\$ bi Fob & & 219 & & 256 & & 242,6 & & 242 & & 225,1 & & \\
\hline Aeroportos & & $\$ \mathrm{R} \%$ & & $\$ \mathrm{R} \%$ & & $\$ R \%$ & & $\$ R \%$ & & $\$$ R \% & & \\
\hline Guarulhos Exportação & & 93,03 & & $4 \quad 9 \quad 3,02$ & & $8 \quad 3,34$ & & 73,47 & & $7 \quad 3,56$ & & \\
\hline Viracopos Exportação & & 141,48 & 3,35 & $17 \quad 1,31$ & & $18 \quad 2,6$ & 2,9 & 171,20 & & $\begin{array}{l}46 \quad 1,5 \\
4\end{array}$ & & \\
\hline
\end{tabular}

Fonte: Elaborada pelos autores, conforme informações do MDIC (2015). Nota: $R=$ Ranking 


\subsection{A evolução do ISSQN em Campinas}

O ISSQN, foco de nossa análise, representa uma importante fonte de arrecadação para os municípios, e faz parte do grupo de receitas tributárias denominadas, em Finanças Públicas, de Fonte (00) ou (01), Recursos Próprios ou ainda Caixa Único. O fato gerador é a prestação de serviços, descritos na Lei Complementar $\mathrm{n}^{\circ} 116$, de 31 de julho de 2003, exercidos por empresas ou profissionais autônomos. A alíquota é variável entre o mínimo de $2 \%$ e o máximo de $5 \%$ com base no preço do serviço prestado. No caso de Campinas, a alíquota do ISSQN é variável de $2 \%$ a $5 \%$, conforme as características dos serviços, mas existem municípios que fixam alíquotas únicas entre o mínimo e o máximo estabelecido por lei.

Por meio da Tabela 4 (APÊNDICE) observa-se que o ISSQN e o ICMS são os impostos mais representativos para a Prefeitura de Campinas. O IPTU foi o segundo imposto mais importante para Campinas entre 1995 e 2004, sendo superado pelo ISSQN desde então. Durante 18 anos, entre 1995 e 2012, o ICMS liderou o ranking da arrecadação tributária em Campinas com uma diferença em relação ao ISSQN, em termos de valores, que oscilou de R $\$ 85$ a R $\$ 100$ milhões até 2009. Desde então essa diferença foi reduzida passando para R \$ 60 milhões em 2010, R \$ 38 milhões em 2011 e R \$ 24 milhões em 2012. E em 2013, pela primeira vez, o ISSQN liderou o ranking da arrecadação tributária em Campinas, enquanto o ICMS passou para a segunda posição e o IPTU para o terceiro lugar.

O crescimento da receita do ISSQN decorre, certamente, do crescimento da economia local, concretização de projetos imobiliários e maior demanda por serviços, com destaque para as obras de construção do novo terminal de passageiros em Viracopos (para 14 milhões de passageiros), na medida em que, devido ao ISSQN, houve a incidência mensal do pagamento de cerca de R $\$ 5$ milhões (R\$ 60 milhões no ano), ver o APÊNDICE. Porém, Campinas vem aumentando a participação dos setores de comércio e serviços na constituição de seu PIB: desde 2005 o ISSQN passou a superar o IPTU em termos de arrecadação tributária (APÊNDICE). É um sinal de que Campinas acompanha a tendência internacional gerada pela dinâmica da economia contemporânea. Nessa economia, ganham importância atividades de logística integrada às operações industriais, bem como uma nova dinâmica de organização das atividades 


\section{ANÁLISE DA EVOLUÇÃO DO IMPOSTO SOBRE SERVIÇOS NA ARRECADAÇÃO}

TRIBUTARIA NO MUNICÍPIO DE CAMPINAS-SP

de comércio e serviços que se intensifica, sobretudo, com apoio das telecomunicações e informática.

Pelas razões abaixo, nos próximos anos há uma tendência em Campinas de manter o crescimento da arrecadação do ISSQN frente ao ICMS, considerando-se, inclusive, que no final de 2013, tivemos US\$ 478,47 milhões de investimentos anunciados no setor de serviços para os próximos três anos. (CAPPA, 2013).

Essa análise está amparada na dinâmica econômica de Campinas, que acompanha a tendência internacional de elevação do setor de serviços na economia contemporânea, bem como nos papéis exercidos pelos grandes aeroportos no século XXI, como infraestrutura que impulsiona, direta e indiretamente, atividades na indústria, comércio e serviços. Caracterizam-se, dessa forma, as relações econômicas entre Campinas e Viracopos, como discutido por meio dos dados empíricos sobre fluxos de passageiros e de transporte de mercadorias exportadas e importadas (Tabelas 1, 2 e 3 ).

Porém, o crescimento do ISSQN em Campinas não deve ser atribuído, exclusivamente, a Viracopos, apesar de que esse aeroporto vem aumentando suas influências na dinâmica econômica e urbana de Campinas e região desde 2008, como o início das operações da empresa aérea Azul, e mais ainda a partir de 2012, com a concessão desse aeroporto para a Aeroporto Brasil Viracopos S/A.

Primeiro, porque, devido, em grande parte, a Viracopos, Campinas e região têm recebido investimentos produtivos no setor de serviços e comércio com destaque para condomínios industriais, centros logísticos, hotéis e shopping center, conforme segue respectivamente: I) US\$ 133,15 milhões na construção do Centro Logístico Brasil - Campinas às margens das rodovias Anhanguera $\mathrm{e}$ Bandeirantes; RS 170 milhões da Celistics, empresa espanhola que responde por cerca de $60 \%$ da logística de celulares produzidos no Brasil, na construção de um centro de armazenagem de $30 \mathrm{mil} / \mathrm{m}^{2}$; GR Campinas 2 (US\$ 36,95 milhões); Parque Empresarial Campinas (US\$ 24,64 milhões) e o Centro Empresarial Bandeirantes (US\$ 11,64 milhões); II) o Grupo The Royal Palm Plaza, que fica a cerca de 10 quilômetros de Viracopos, investiu R $\$ 400$ milhões na construção de um centro de convenções para 10 mil pessoas, dois hotéis, um mal com 30 lojas e um prédio de escritórios, implantação de Universidade Hotel (US\$29,10 milhões) e dos Hotéis Deville (US\$ 19,95 milhões); e III) a construção do Parque das Bandeiras Shop- 
ping com 320 mil m² e R\$ 450 milhões na Região do Campo Grande que se localiza no entorno de Viracopos.

Segundo, porque a Secretaria de Finanças de Campinas aumentou a fiscalização do fato gerador do ISSQN por meio da Nota Fiscal de Serviços Eletrônica (NFS-e) que substituiu a nota fiscal impressa. Os investimentos em tecnologia da informação permitiram melhor controle e fiscalização, modernização e eficiência da máquina fazendária. Com isso, houve agilidade no processo de apuração do ISSQN e também aumento do número de emissões de notas fiscais de serviços, porque a Prefeitura de Campinas passou a conceder premiações mensais por meio de sorteios para os cidadãos que solicitam nota fiscal de serviços.

Não obstante, teremos outras obras de ampliação do Aeroporto de Viracopos sinalizando para a manutenção de sua importância para o aumento da arrecadação de ISSQN para Campinas. São exemplos, a construção de mais três pistas de pouso e decolagem em uma área que passará dos atuais $8,34 \mathrm{~km}^{2}$ para $25,99 \mathrm{~km}^{2}$. A ampliação de Viracopos será realizada em cinco etapas, de acordo com o crescimento da demanda: I) 14 milhões de passageiros previstos para 2014; II) 22 milhões de passageiros para 2018; III) 45 milhões de passageiros para 2024; IV) 65 milhões de passageiros para 2033; e V) 80 milhões de passageiros para 2038.

\section{CONCLUSÃO}

Neste estudo, observou-se que Campinas acompanha tendência internacional gerada pela dinâmica da economia contemporânea. Nessa economia, ganham importância, especialmente, atividades de logística integrada às operações industriais, bem como uma nova dinâmica de organização das atividades de comércio e serviços. Sinais nessa direção é que, desde 2005, o ISSQN passou a superar o IPTU em termos de arrecadação tributária, e, desde 2010, passou a diminuir a diferença, em termos de valores, em relação ao ICMS: R \$ 60 milhões em 2010, R \$ 38 milhões em 2011 e R \$ 24 milhões em 2012.

Diante das considerações acima é possível afirmar que nos próximos anos há uma tendência de manutenção do crescimento da arrecadação do ISSQN frente ao ICMS. Para o Poder Público Municipal torna-se importante organizar políticas públicas de gestão aeroportuária, na medida em que a dinâmica econômica e urbana de 


\section{ANÁLISE DA EVOLUÇÃO DO IMPOSTO SOBRE SERVIÇOS NA ARRECADAÇÃO TRIBUTARIA NO MUNICÍPIO DE CAMPINAS-SP}

Campinas e região tende a, cada vez mais, ser influenciada pelo o que vier a ocorrer com Viracopos e seu entorno.

Primeiro, para ordenar a dinâmica urbana e econômica e evitar deseconomias de aglomeração geradas pelo intenso fluxo de passageiros e de mercadorias em direção a Viracopos, como perdas de qualidade de vida e impactos negativos na atração e expansão de investimentos produtivos que utilizam o transporte aéreo como parte de suas estratégias de inovação, produção e comercialização de produtos no mercado mundial.

Segundo, para elaborar políticas e ações que multipliquem os efeitos do emprego, da renda e dos tributos relacionados a Viracopos e às atividades das empresas aéreas que atuam no aeroporto. Desse modo, é possível ao Poder Executivo Municipal coordenar e integrar ações entre seus órgãos, a Aeroportos Brasil S/A e sensibilizar os poderes estadual e federal para evitar futuros obstáculos à mobilidade urbana e à movimentação dos fluxos de mercadorias e pessoas em direção a Viracopos.

\section{REFERÊNCIAS}

BRASIL. Presidência da República. Lei Complementar no 116, de 31 de junho de 2003. Dispõe sobre o Imposto Sobre Serviços de Qualquer Natureza, de competência dos Municípios e do Distrito Federal, e dá outras providências. Diário Oficial da União, Brasília, DF, 2003.

\section{República Federativa do Brasil. Constituição Federal de} 1988. Brasília, DF: Senado Federal, 1988.

CANO, W.; BRANDÃO, C. (Coord.). A RMC: urbanização, economia, finanças e meio ambiente. Campinas, SP: Ed. Unicamp, 2002.

CAPPA, J. Campinas e Viracopos: uma requalificação da metrópole no século XXI? In: SOUZA, M. (Org.). A metrópole e o futuro: refletindo sobre Campinas. Campinas, SP: Edições Territoriais, 2008.

Alínea, 2013.

Cidades e aeroportos no século XXI. Campinas, SP:

CÓSSIO, F.; CARVALHO, L. Os efeitos expansivos das transferências intergovernamentais e transbordamentos espaciais de despesas públicas: evidências para os municípios brasileiros. Pesquisa e Planejamento Econômico, São Paulo, v. 31, n. 1, p. 75-124, 2001. 
COSTA, R.; CASTELAR, L. O impacto das transferências constitucionais sobre os gastos dos municípios brasileiros. Análise Econômica, Porto Alegre, n. 64, p. 171-189, set. 2015.

ECO, U. Como se faz uma tese. São Paulo: Perspectiva, 1993.

FACHIN, O. Fundamentos da metodologia. São Paulo: Atlas, 1993.

FUNDAÇÃO SISTEMA ESTADUAL DE ANÁLISE DE DADOS. A reforma tributária de 1988 e os municípios do Estado de SãoPaulo. São Paulo, 1993. (Coleção Estudos Municipais).

INSTITUTO BRASILEIRO DE GEOGRAFIA E ESTATÍSTICA. Regiões de influências das cidades. Rio de Janeiro, 2007. Disponível em:<www.ibge.org.br>. Acesso em: 20 jul. 2008.

LOPREATO, F.; PAIVA, C. Região Metropolitana de Campinas: evolução das finanças públicas. Texto para discussão, Campinas, SP, n. 105, nov. 2001.

MAX, H. Investigación econômica, su metodologia y su técnica. México: Fondo de Cultura Cconómica, 1975.

MUNHOZ, D. Economia aplicada: técnicas de pesquisa e análise econômica. Brasília, DF: Ed. UnB, 1989.

PEREIRA, J. Finanças públicas. São Paulo: Atlas, 1999.

SÃO PAULO (Estado). Lei complementar 870 de 19 de junho de 2000: Cria a Região Metropolitana de Campinas. São Paulo: Assembleia Legislativa, 2009.

SELLTIZ, C.; JAHODA, M.; DEUTSCH, M.; COOK, S. Métodos de pesquisa nas relações sociais. São Paulo: Editora Pedagógica e Universitária, 1974.

SERRA, J.; AFONSO, J. Federalismo fiscal à brasileira: algumas reflexões. Revista do BNDES, Rio de Janeiro, v. 6, n. 12, p. 3-30, dez. 1999. - ver quem são os autores.

SOLA, G.; BONACIMA, C. O processo orçamentário e a tomada de decisão de gestores em um hospital público. Revista Contabilidade e Organizações, São Paulo, 25, p. 32-42, 2015. 


\section{ANÁLISE DA EVOLUÇÃO DO IMPOSTO SOBRE SERVIÇOS NA ARRECADAÇÃO}

TRIBUTARIA NO MUNICÍPIO DE CAMPINAS-SP

TRISTÃO, J. A. A administração tributária dos municípios

brasileiros: uma avaliação do desempenho da arrecadação. 2003. 181 f. Tese (Doutorado em Administração) - Pós-Graduação da Escola de Administração de Empresas de São Paulo, Fundação Getúlio Vargas, São Paulo, 2003.

\section{NOTA:}

Os autores agradecem ao João Carlos Ribeiro, Contador e Diretor do Departamento de Finanças da Prefeitura Municipal de Campinas, pelas opiniões técnicas sobre o tema. A análise contida neste artigo é de inteira responsabilidade de seus autores. 


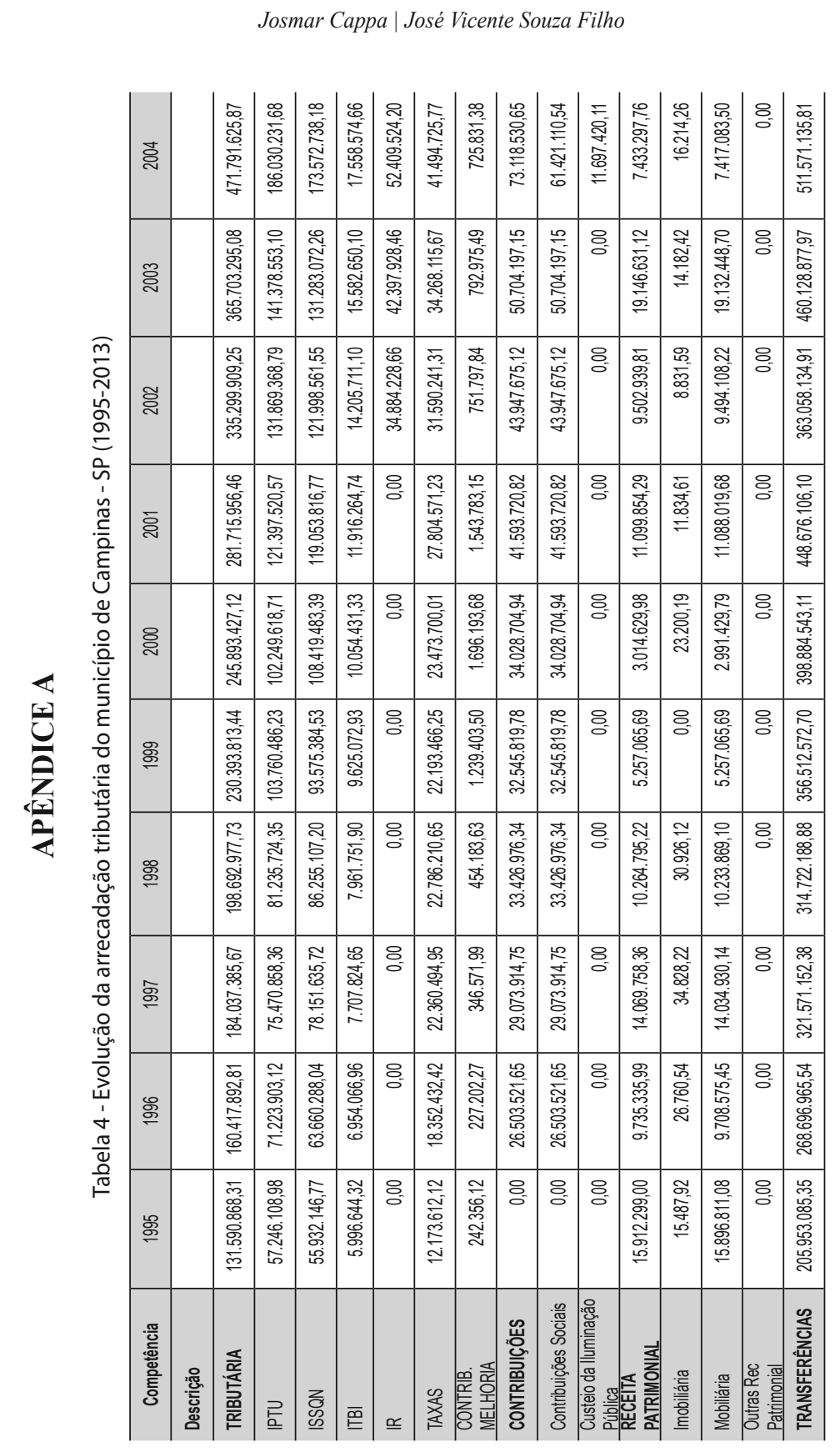


ANÁLISE DA EVOLUÇÃO DO IMPOSTO SOBRE SERVIÇOS NA ARRECADAÇÃO TRIBUTARIA NO MUNICÍPIO DE CAMPINAS-SP

\begin{tabular}{|c|c|c|c|c|c|c|c|c|c|c|c|c|c|}
\hline 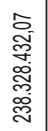 & 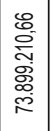 & 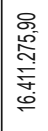 & 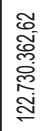 & \begin{tabular}{|l|} 
\\
0 \\
0 \\
0 \\
0 \\
0 \\
0 \\
$\infty$ \\
$\infty$
\end{tabular} & & 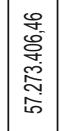 & 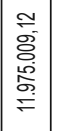 & 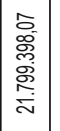 & 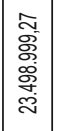 & 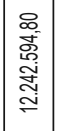 & & 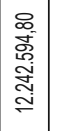 & \\
\hline & 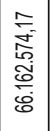 & 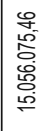 & 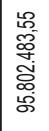 & 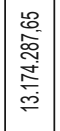 & & 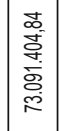 & 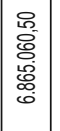 & 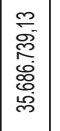 & 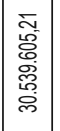 & 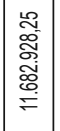 & 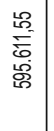 & 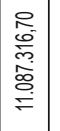 & \\
\hline 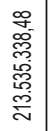 & 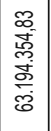 & 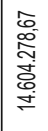 & 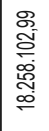 & 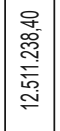 & & & 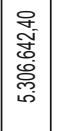 & 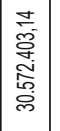 & 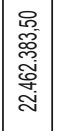 & 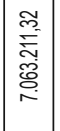 & 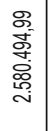 & 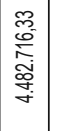 & \\
\hline స్ట్రి & 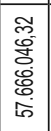 & 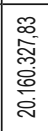 & 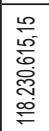 & 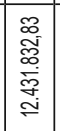 & & 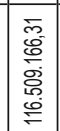 & 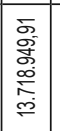 & 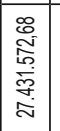 & 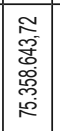 & 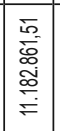 & 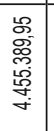 & 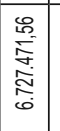 & \\
\hline $\begin{array}{l}0 \\
0 \\
0 \\
0 \\
0 \\
0 \\
0\end{array}$ & $\begin{array}{l}\text { I } \\
06 \\
08 \\
0 \\
0 \\
0 \\
0 \\
\text { o }\end{array}$ & 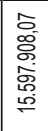 & 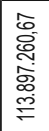 & 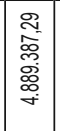 & 응 & 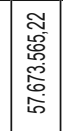 & 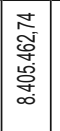 & 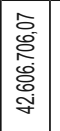 & 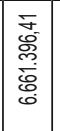 & 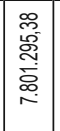 & 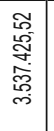 & 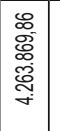 & \\
\hline 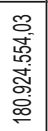 & 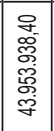 & 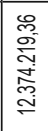 & 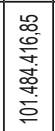 & 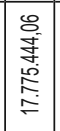 & 응 & 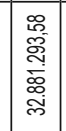 & 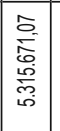 & 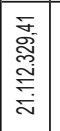 & 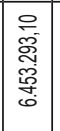 & 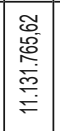 & 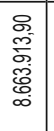 & 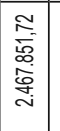 & . \\
\hline 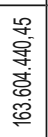 & 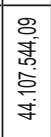 & 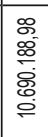 & 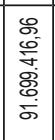 & 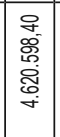 & 응 & 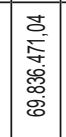 & 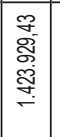 & 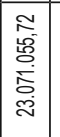 & 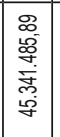 & 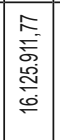 & 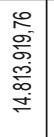 & 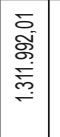 & \\
\hline 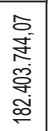 & 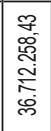 & 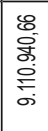 & 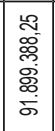 & 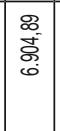 & 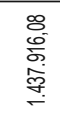 & 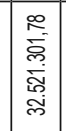 & 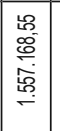 & 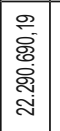 & 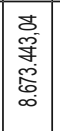 & 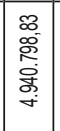 & 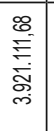 & 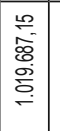 & 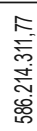 \\
\hline 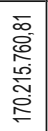 & 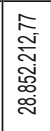 & 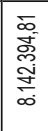 & 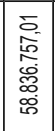 & 要 & 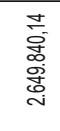 & 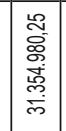 & 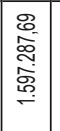 & 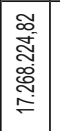 & 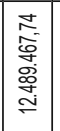 & 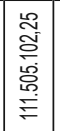 & 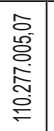 & 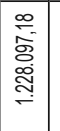 & 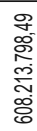 \\
\hline 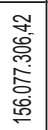 & 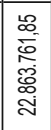 & 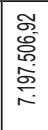 & 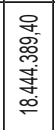 & 응 & 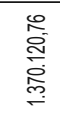 & 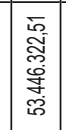 & 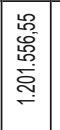 & 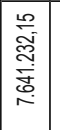 & 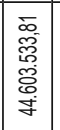 & 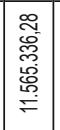 & 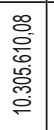 & 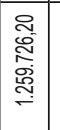 & 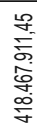 \\
\hline & & อิ & & 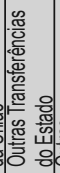 & 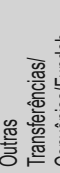 & & & 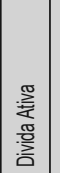 & 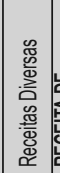 & | & 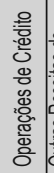 & 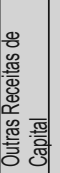 & \\
\hline
\end{tabular}




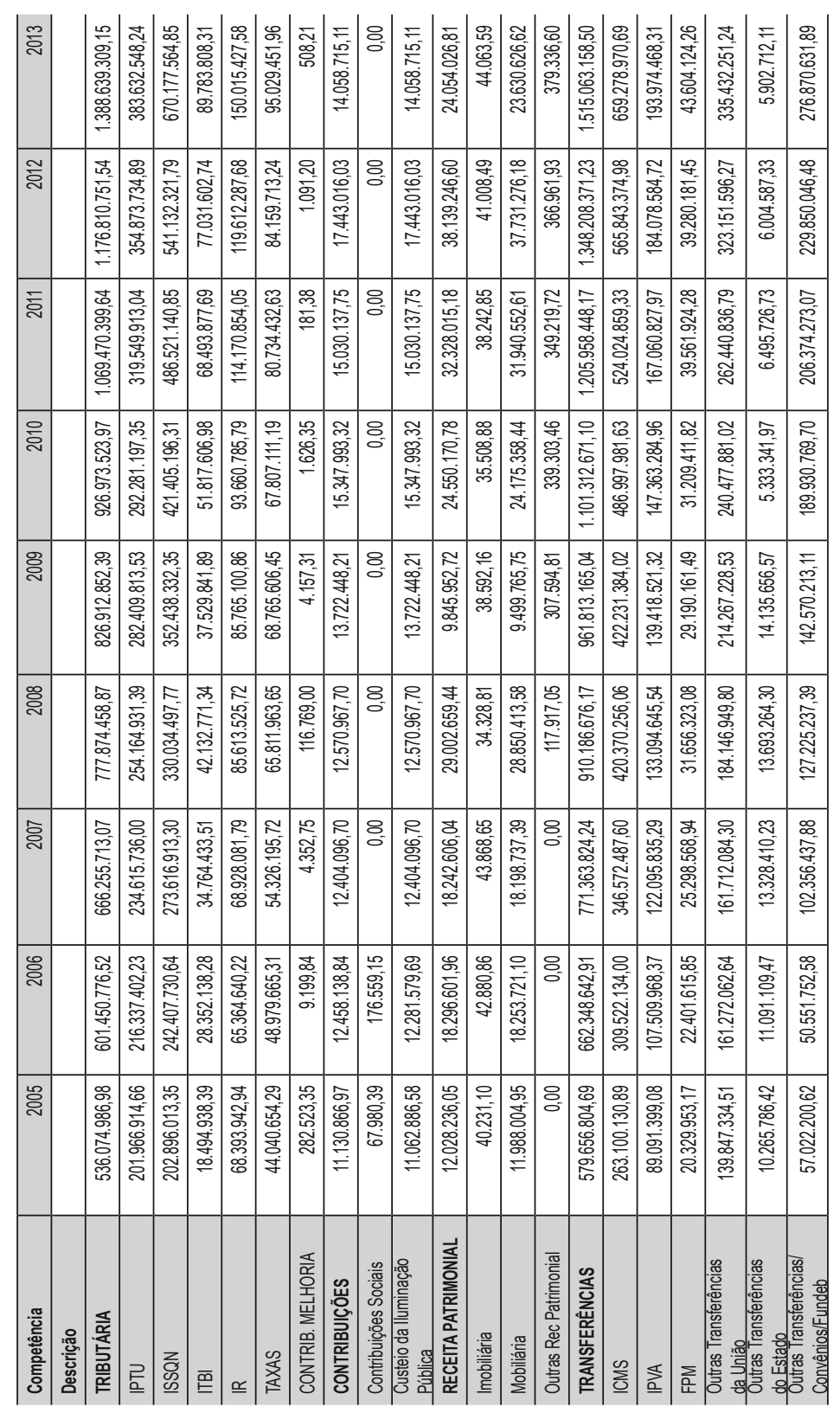


ANÁLISE DA EVOLUÇÃO DO IMPOSTO SOBRE SERVIÇOS NA ARRECADAÇÃO TRIBUTÁRIA NO MUNICÍPIO DE CAMPINAS-SP

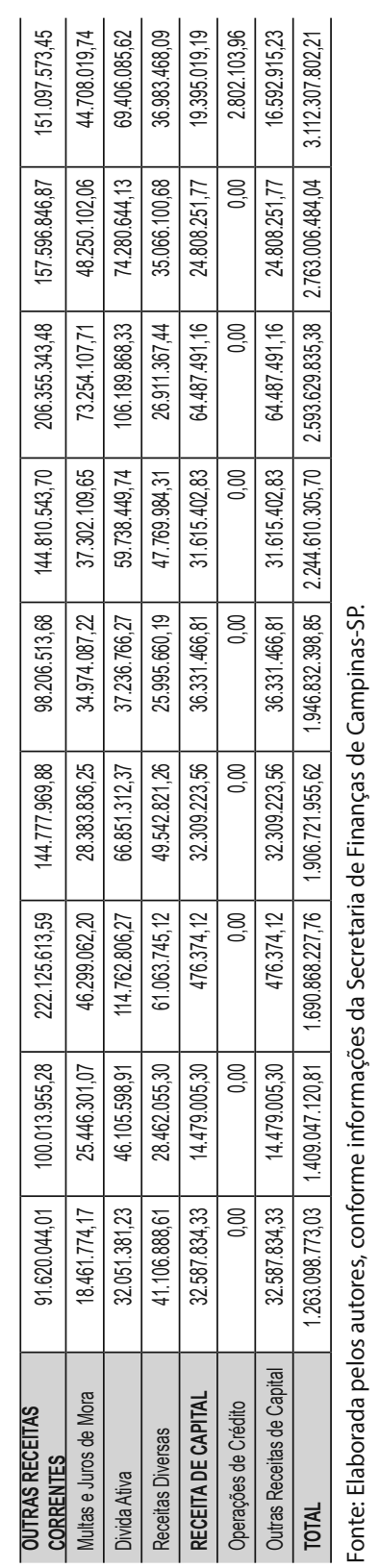


